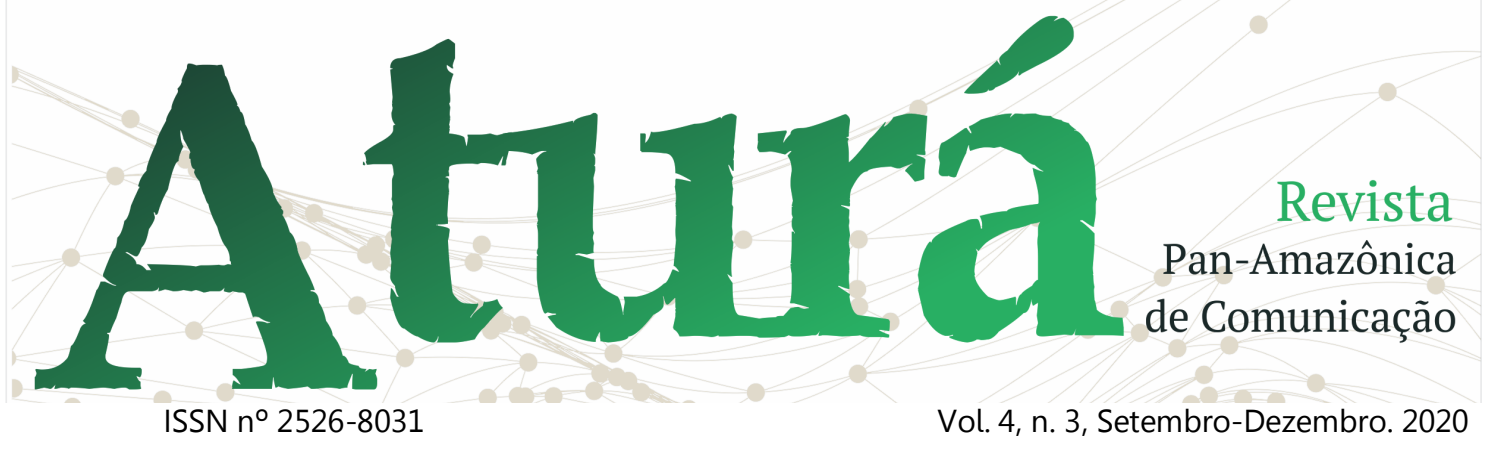

\title{
FENOMENOLOGIA E HERMENÊUTICA: A CIÊNCIA DA COMUNICAÇÃO VISTA POR OUTRAS LENTES
}

Phenomenology and Hermeneutics: the science of communication seen by other lenses

Fenomenología y Hermeneutica: la ciencia de la comunicación vista por otros lentes

\section{Marilena Barbosa de Freitas ${ }^{1}$}

\section{RESUMO}

Este trabalho mostra que a fenomenologia e a hermenêutica no campo epistemológico das investigações científicas se constituem como um caminho pavimentado para desconstruir a crença da ciência normal, fundamentada na racionalidade, como única alternativa para se chegar à objetivação histórica da verdade. Mais do que desconstruir, a fenomenologia e a hermenêutica, ambas e aliadas, mostram o que está subjacente à aparente verdade, inclusive nas ciências da comunicação, já que "(...) toda consciência é consciência de algo", e sendo assim, há intencionalidade em todo e qualquer processo comunicacional.

PALAVRAS-CHAVE: Fenomenologia; Hermenêutica; Ciências da Comunicação.

\begin{abstract}
This work shows that phenomenology and hermeneutics in the epistemological field of scientific investigations constitute a paved path to deconstruct the belief of normal science, based on rationality, as the only alternative to reach the historical objectification of truth. More than deconstructing, phenomenology and hermeneutics, both and allies, show what underlies the apparent truth, including in the communication sciences, since

\footnotetext{
${ }^{1}$ Mestranda em Comunicação pelo Programa de Pós-Graduação em Comunicação da Universidade Federal de Roraima, Linha de Pesquisa: Memória e Identidades. Possui graduação em Comunicação Social: Habilitação em Jornalismo pela Universidade Federal de Roraima (2001). É especialista em Assessoria de Comunicação pelo Centro Universitário Estácio da Amazônia (2017). Especialista em Representação Parlamentar pelo Centro Universitário de Ensino Superior do Amazonas - Ciesa (2019). Atualmente é Gerente do Núcleo de Jornalismo da Assembleia Legislativa de Roraima. E-mail: marilenafreitasrr@gmail.com.
} 


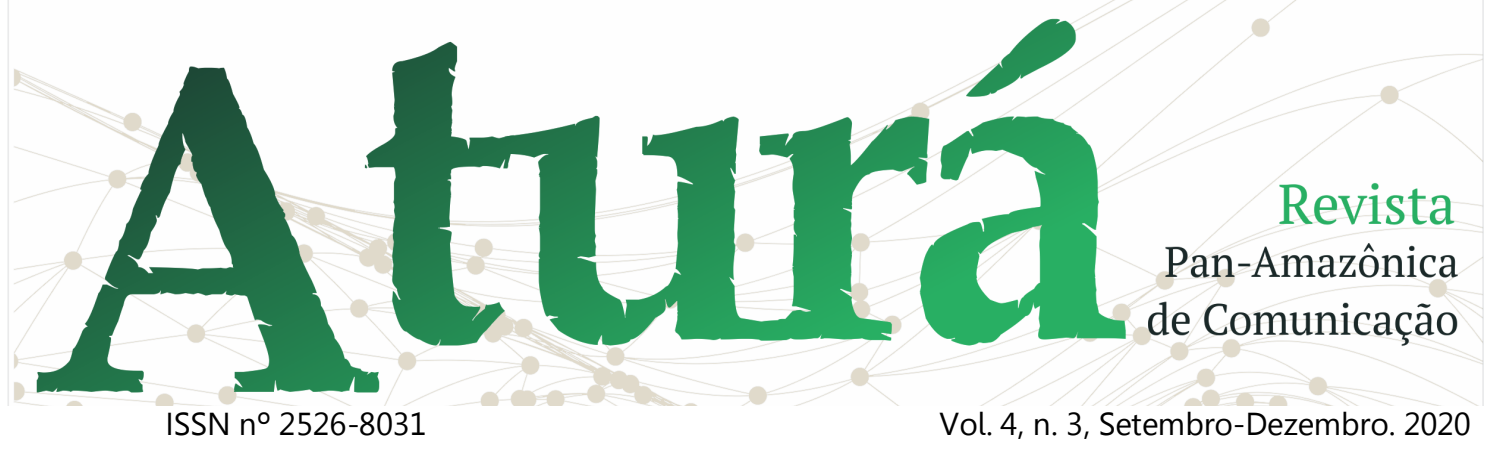

"(...) all consciousness is awareness of something", and thus, there is intentionality in any communication process.

KEYWORDS: Phenomenology; Hermeneutics; Communication Sciences.

\section{RESUMEN}

Este trabajo muestra que la fenomenología y la hermenéutica en el campo epistemológico de las investigaciones científicas constituyen un camino pavimentado para deconstruir la creencia de la ciencia normal, basada en la racionalidad, como única alternativa para alcanzar la objetivación histórica de la verdad. Más que deconstruir, la fenomenología y la hermenéutica, ambas y aliadas, muestran lo que subyace a la verdad aparente, incluso en las ciencias de la comunicación, ya que "(...) toda conciencia es conciencia de algo", y por tanto, hay intencionalidad en cualquier proceso de comunicación.

PALABRAS-CLAVE: Fenomenología; Hermenéutica; Ciencias de la comunicación.

\section{Introdução}

O propósito deste artigo é mostrar que as abordagens fenomenológica e hermenêutica, ainda pouco inexplorada no campo das pesquisas em comunicação podem trazer um novo olhar sobre os processos que envolvem as relações comunicacionais.

A fenomenologia e a hermenêutica são campos de estudos da filosofia, e como tal, abre um leque para as novas formas de pensamento, de pensar fora da caixinha, fora da lógica da ciência tradicional, que pauta as pesquisas qualitativas e quantitativas na lógica da razão, que de certa forma salvaguarda a pesquisa, para atender o "todo", deixando a subjetividade em segundo plano, prejudicando desta forma os organismos heterogêneos, as particularidades que estão inseridas no todo.

Neste contexto, a fenomenologia como filosofia transcendental é a ciência das essências, que foge às regras do cálculo. A sensibilidade da fenomenologia aliada à hermenêutica auxilia o indivíduo a decifrar, entender o seu ser no mundo. O dansei (ser-aí), em que $o$ indivíduo é este ser-aí-no-mundo, comprova que a existência deste ser está 


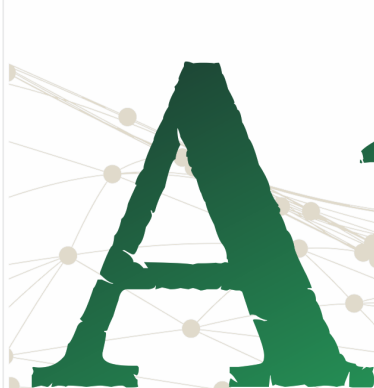

ISSN n²526-8031
Revista

Pan-Amazônica

de Comunicação sempre na lógica do estar com o outro, que é um processo inerente às relações comunicacionais, vivenciadas no quotidiano, nas infinitas experiências com o outro.

Para exemplificar este processo, usamos a brasileiríssima teoria da Folkcomunicação, excelente ponto de partida para refutar modelos preestabelecidos, assentados na "ciência normal". Por fim, entendemos que a fenomenologia e a hermenêutica são abordagens que permitem um novo olhar na condução da pesquisa, e em especial, pesquisas em comunicação que necessitam das lentes que vão permitir ver o ser-com-outros, principalmente na Amazônia, como tentativa de entender o que está por trás, subjacente nas consciências que brotam por meio das memórias e dos saberes imanentes ao ser-aí amazônico.

\section{Origem da Fenomenologia e da} Hermenêutica

Os estudos fenomenológicos tiveram início no final do século XIX com o filósofo alemão Edmundo Husserl (1986), e tomaram corpo a partir do século $X X$, com severas críticas às ciências naturais, à ciência da razão baseada no método cartesiano, aplicado à ciência desde o século XVII.

$O$ termo fenomenologia é antigo e data do século $\mathrm{XVI}$, mencionado pela primeira vez pelo filósofo suíço Johann Heinrich Lambert (2008), para "ciência das aparências", seguido por Kant (2008) para explicar conceitos da metafísica, e Hegel (2008) no livro Fenomenologia do Espírito, publicado em 1807 (GOMES et al, 2008, p.3).

Mas foi Husserl (1986) que desafiou os métodos científicos, já totalmente utilizados pelos cientistas e pesquisadores, a partir do surgimento do Iluminismo no século XVIII, e que era a base metodológica de toda pesquisa científica, ainda sendo, até os dias atuais, em diversos campos de pesquisa.

As ideias husserlianas trazem à baila uma reflexão sobre a fenomenologia transcendental, que perpassa os sentidos da imanência e se 


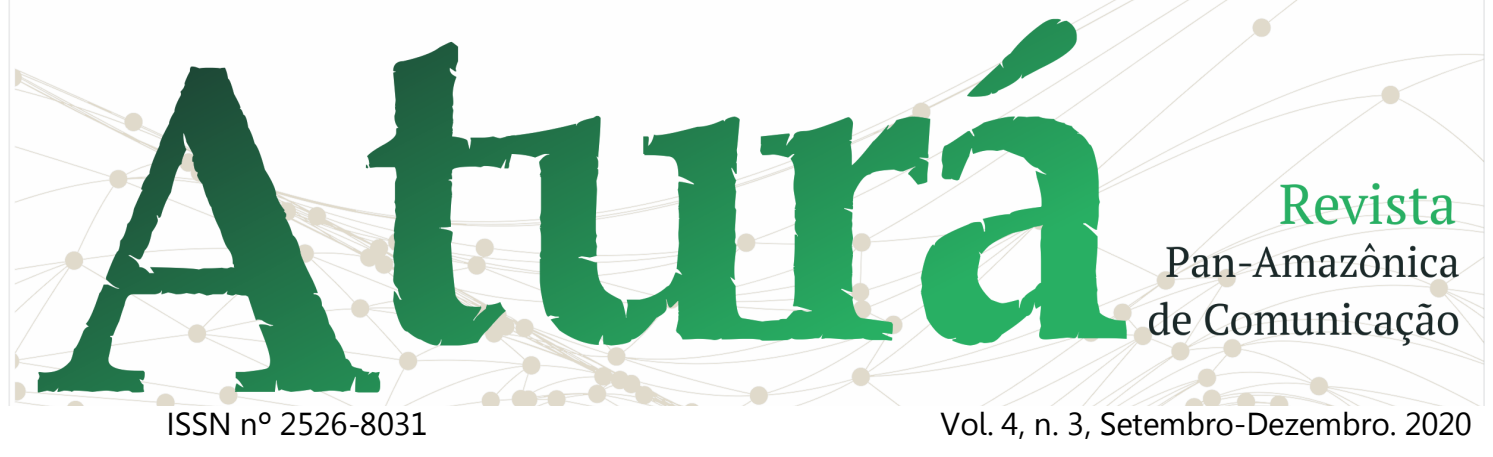

orienta pela materialidade e os sentimentos. O que o filósofo propõe é estudar os fenômenos tais como se apresentam para o sujeito, observados a partir da consciência deste sujeito. Dessa forma, ele dá um caráter subjetivo ao fenômeno quando o observa a partir da consciência do sujeito.

$\mathrm{Na}$ tradução de Artur Morão, Husserl afirma que "a fenomenologia transcendental é fenomenologia da consciência constituinte, e, portanto, não lhe pertence sequer um único axioma objectivo" (HUSSERL. 1986, p.14) e que a interpretação do conhecimento na "senda da ciência objectiva" é passível de lacunas, de aparentes 'verdades'.

O conhecimento do universal é algo de singular, é sempre um momento na corrente da consciência; o próprio universal, que aí é dado na evidência, não é algo de singular, mas, sim, universal, portanto, transcende em sentido verdadeiro (HUSSERL. 1986, p.12)

Para compreender os fenômenos a partir dos estudos fenomenológicos, é preciso se desprender das leis universais, dos postulados científicos das ciências naturais, deixar a racionalidade, não necessariamente em segundo plano, mas ouvir, enxergar com as lentes da alteridade, tirando as amarras, como sugere Juremir Silva (2010, p.17), "(...) por meio do estranhamento, sair dos seus quadros teóricos antes de entranha-se no conhecido familiar do cotidiano", é o que orienta a redução fenomenológica.

O filósofo convida a comunidade científica a uma reflexão acerca dos axiomas epistemológicos e garante que a própria crítica ao conhecimento, em si, já é um método fenomenológico, uma vez que o próprio conhecimento suscita dúvida ao cogitar uma hipótese à luz da ciência do conhecimento.

"O apreender e o ter intuitivos directos da cogitatio já são um conhecer", e partindo deste princípio "as cogitationes são os primeiros dados absolutos" (HUSSERL, 1986, p.23). O pensamento husseliano não aceita 0 mesmo rigor metodológico desenvolvido pela ciência positivista, cujo campo de análise ao método experimental é limitado. A proposta de Husserl é a análise da consciência, já que a 


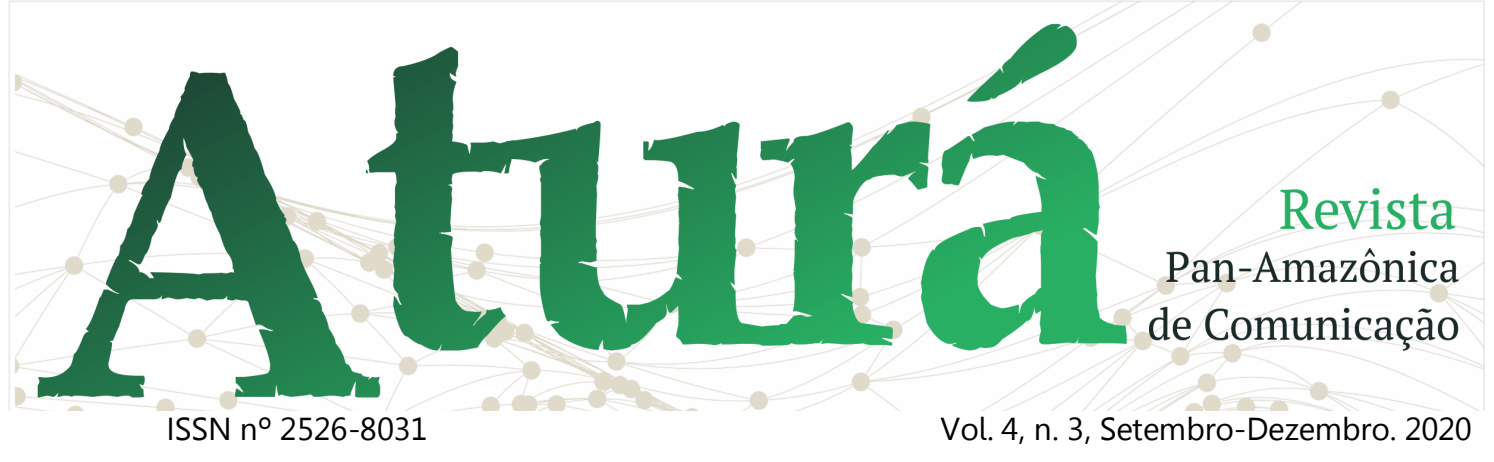

fenomenologia explora outras regiões que o método experimental refuta.

O método de Husserl consiste em estudar a ciência das coisas tais como elas são percebidas no mundo, tal como o sujeito apreende essa informação a partir de sua consciência. Ele parte do princípio de que "toda consciência é consciência de algo", sendo assim, aqui reside o princípio da intencionalidade.

Adianta-se que a aplicabilidade do método fenomenológico não é uma tarefa fácil. $\mathrm{O}$ fato de fazer uma pesquisa sem juízo de valor constitui um exercício de difícil resolução sem ter por base os métodos analíticos da ciência racional. Husserl ressalta que ao investigar esses dados é preciso estar atento ao que está sendo posto, haja vista que "toda a vivência intelectiva e toda a vivência em geral, ao ser levada a cabo, pode fazer-se objecto de um puro ver e captar e, neste ver, é um dado absoluto" (HUSSERL, 1986, p.55).
2 Hermenêutica: ponto de partida para interpretar o ser-aí

A palavra Hermenêutica (hermeneuein) é de origem grega e significa a arte ou técnica de interpretar e explicar um texto, um discurso, um determinado objeto sob a ótica de que apreende esse objeto. Com base em Richardson (2017) a palavra hermenêutica está relacionada ao deus Hermes, que na mitologia grega é o deus da eloquência, o mestre da oratória.

O mensageiro "pés rápidos" dos deuses
do Olimpo, que para dominar a
linguagem dos deuses, tinha,
necessariamente, de compreender e
interpretar as mensagens divinas, traduzi-
las e articulá-las de acordo com as
intenções e necessidades dos seres
terrenos (RICHARDSON, 2017, p.44).

$\mathrm{Na}$ filosofia, a hermenêutica se preocupa em elucidar por meio da interpretação duas distintas vertentes: a epistemológica, com a interpretação de textos e a ontológica, que remete para a interpretação de uma realidade, como ressalta Richardson (2017, p. 45), sendo "(...) adequada não apenas aos domínios religiosos e humanísticos, mas também às ciências sociais emergentes". 


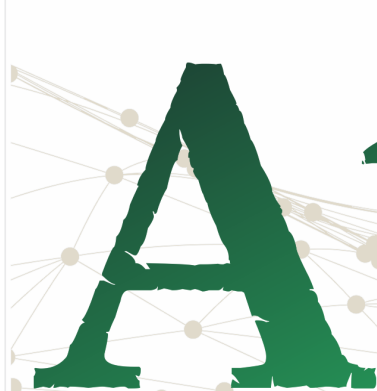

ISSN n $2526-8031$
Revista

Pan-Amazônica

de Comunicação

Vol. 4, n. 3, Setembro-Dezembro. 2020

Foi no período renascentista (XV e $\mathrm{XVI}$ ) que os estudos hermenêuticos se desenvolveram como metodologia de interpretação com o filólogo Friedrich Schleiermacher (2017), passando a ser considerada uma teoria ou epistemologia da interpretação, pois mostra que é possível desenvolver o método científico distinguindo as ciências do espírito, do método das ciências da natureza.

Richardson ressalta (2017, p.45) que a hermenêutica tem um papel fundamental quando analisa "textos e narrativas temporais, ou mistificados pela ideologia e pela falsa consciência". Sua principal função neste contexto é "interpretar sistematicamente para poder revelar a coerência subjacente e o seu verdadeiro sentido.

\section{As Ciências da Comunicação numa} abordagem fenomenológica

e hermenêutica

Falar sobre o que é comunicação aparentemente parece fácil. De acordo com o dicionário Online de Português, a palavra comunicação é um substantivo feminino que significa a "ação ou efeito de comunicar, de transmitir ou de receber ideias, conhecimento, mensagens", ou seja o ato de compartilhar informações, em que o emissor emite a mensagem e o receptor decodifica, ação que pode envolver a presença de dois ou mais indivíduos, portanto relacionada ao Dasein, com a existência do outro, afinal, inexiste comunicação sem o outro. A partir desta definição é perceptivo que tudo é comunicação, que ela é uma ação inerente não somente às relações humanas, mas também as chamadas relações ecológicas, que envolvem os demais seres vivos.

No campo das relações humanas a comunicação é o meio que permite os indivíduos se comunicarem em diferentes linguagens. Como defende Lair Ribeiro (2002, p.11), "comunicação é, depois da sobrevivência física, a mais básica e vital de todas as necessidades". Menina empoderada, a comunicação, portanto, atravessa todos os campos das atividades humanas. 


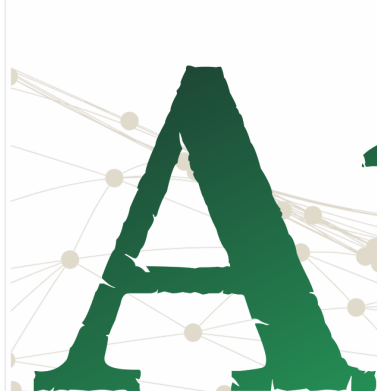

ISSN n $2526-8031$

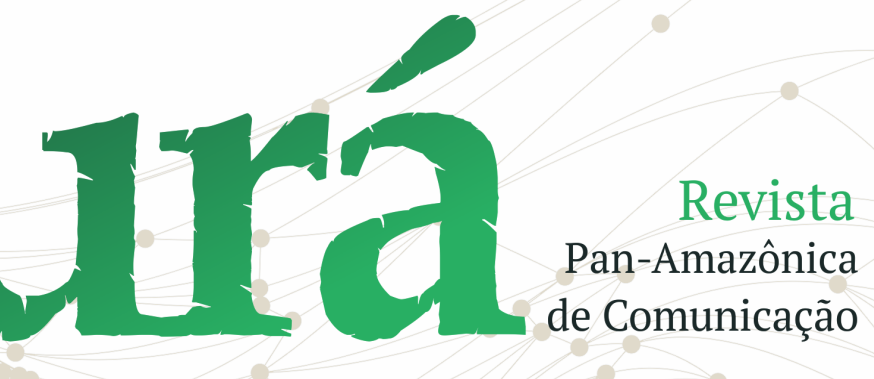

Vol. 4, n. 3, Setembro-Dezembro. 2020
Por estar presente em todas as pesquisas científicas, as relações comunicacionais parecem tão comum, em um primeiro momento, que somente no século passado, na década de 70, surgiram as primeiras pesquisas em comunicação desenvolvidas a partir dos modelos administrativo e crítico das correntes americana e europeia, respectivamente (WOLF,1985).

No Brasil o professor Luiz Beltrão (1999) foi quem deu os primeiros passos e apontou os rumos para o reconhecimento da pesquisa em comunicação como Ciência da Comunicação na década de 60. Uma das contribuições que marcou um ciclo foi a brasileiríssima teoria de comunicação Folkcomunicação, que desnuda um campo de pesquisa em comunicação, na época inexplorado. Esses complexos objetos de estudo, que envolvem os grupos heterogêneos, geralmente encontrados na cultura popular, são abarcados pela Folkcomunicação, teoria muito utilizada na América Latina, e cada vez mais emergente no século atual.
É que o estudo da Folkcultura foca nas culturas marginais, aquelas que são alijadas do processo e estão sempre subjacentes frente a cultura homogênea, padronizada e feita para todos. Neste contexto, quem não se adéqua fica à margem do processo. Esse tipo de objeto de estudo se encaixa numa abordagem fenomenológica, uma vez que essas culturas e saberes populares, estudados pelo método fenomenológico, poderão trazer à tona elementos importantes do processo comunicacional a partir das camadas, até então, invisíveis nas pesquisas do método racional, tais como elas são na essência, uma vez que a
A Folkcomunicação é o estudo dos procedimentos comunicacionais através dos quais as manifestações da cultura popular ou do folclore se expandem, sociabilizam-se, convivem com outras cadeias comunicacionais, sofrem modificações por influência da comunicação massificada e industrializada ou se modificam quando apropriadas por tais complexos (HOHLFELDT apud Maciel e Sabbatini, 2002, p.217).

Com base na Teoria da Folkcomunicação observa-se que as interfaces da comunicação requerem pesquisas com olhares transdisciplinares 


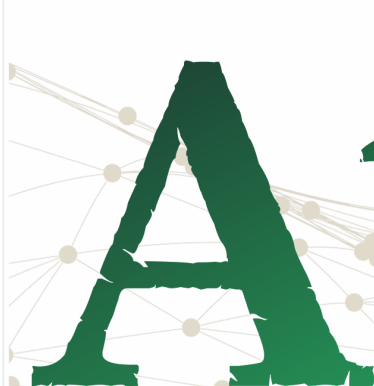

ISSN n² 2526-8031
Revista

Pan-Amazônica

de Comunicação

Vol. 4, n. 3, Setembro-Dezembro. 2020

e metodologias que atendam e tragam, além de clareza para a pesquisa, utilidade na aplicação em prol de mudanças que contribuam para o bem-estar político, econômico e social. Como defende Calhoun (2011, citado por Rebouças, 2012, p.06) "(...) a Comunicação é heterogênea não apenas na mistura de campos que incorpora, mas nos modelos organizacionais e curriculares que produziu por si mesma". Em tom até irônico, ele enfatiza que padronizar uma metodologia para as "pesquisas em Comunicação é risível".

A criação da Escola Latinoamericana de Comunicação, pontua José Marque de Melo (1999), foi fundamental e deixou um legado para a América do Sul. Mas nossa realidade é muito heterogênea, e a partir da Escola Latinoamericana, um grito ecoou, deixando claro que a contribuição dessas correntes é inegável, mas que os latinos americanos têm suas particularidades, e com elas, métodos que vão ao encontro das pesquisas em comunicação deste continente.
Ao observar a amplitude dos processos comunicacionais e da subjetividade presente que envolve os estudos de comunicação, percebe-se que a fenomenologia, ao explorar a visão subjetiva do mundo, aliada à hermenêutica, são importantes caminhos no campo da pesquisa em comunicação.

Castro (2013) contribui com essa discussão quando pesquisa a contribuição da fenomenologia da comunicação na quotidianidade, com base no pensamento de Heidegger (1927) ao citar o pensamento de Boutot (1989) quando analisa a expressão Daisen (ser aí no mundo, ou seja, nunca desacompanhado) quando ele defende que, "(...) Mesmo só, mesmo quando não tem nenhum outro ser na sua proximidade imediata, o Dasein está, sempre, com alguém. A solidão não tem sentido, a bem dizer, senão para um ser que está, fundamentalmente, em relação com outros" (BOUTOT, 1989, p.29). Em outras palavras podemos afirmar que até a solidão é ilusória, haja vista que nossos pensamentos estão com o outro, em uma 


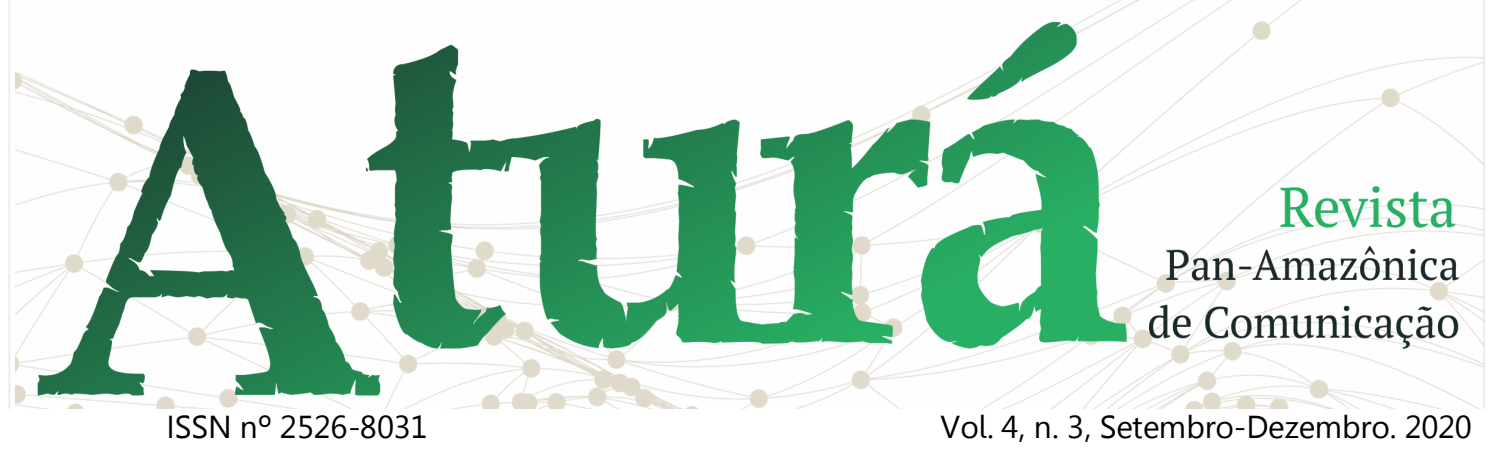

comunicação não verbal, mas transendental.

Aliás, Halbwachs (1990, p.12), quando fala da memória individual enfatiza que as memórias são constituídas nas relações sociais. Isso não seria o Daisen? O ser-aí com o outro no cotidiano? "A memória individual existe, mas ela está enraizada dentro dos quadros diversos que simultaneidade ou a contingência reaproxima momentaneamente".

Diante do exposto, podemos aferir que a comunicação midiatizada reforça o Daisen, à medida que trabalha o confrontamento de ideias e opiniões, levando automaticamente o indivíduo a tomar posicionamentos, ser-aí-com-ooutro, podendo surgir nessas relações de coletividade certos fenômenos, idealizados por grupos organizados que, imbuídos e embebecidos por uma ideia comum entre os seus, transformam homens em mitos.

Ao mergulhar nos estudos hermenêuticos, Richardson (2017) cita vários filósofos que tratam sobre a

hermenêutica como Wilhelm Dilthey, Paul Ricoeur e Hans Gadamer. O primeiro desta lista esclarece que a hermenêutica tal qual um fenômeno não surgiu da noite para o dia, mas de forma lenta foi se maturando, semelhante aos métodos empíricos.

\begin{abstract}
E do debate entre estas regras, da luta entre orientações distintas a respeito da interpretação de obras de importância vital e da necessidade assim determinada de fundamentar estas regras surgiu a ciência hermenêutica. Ela é o corpo de ensinamentos sobre a arte (Kunstlehre) da interpretação de monumentos literários (DILTHEY.1999, p,16).
\end{abstract}

Para ratificar que a hermenêutica é de fundamental importância, Dilthey (1999) garante que somente este conhecimento é capaz de decifrar por meio da compreensão o que uma pessoa disse e o que ela própria não compreendeu. E esse comportamento é comum nas relações sociais. Inclusive traz como exemplos determinadas situações em que o sujeito pergunta a si próprio porque falara ou cometera determinada situação.

Concebida na conjunção entre teoria do conhecimento, lógica e metodologia das ciências humanas, esta teoria da 


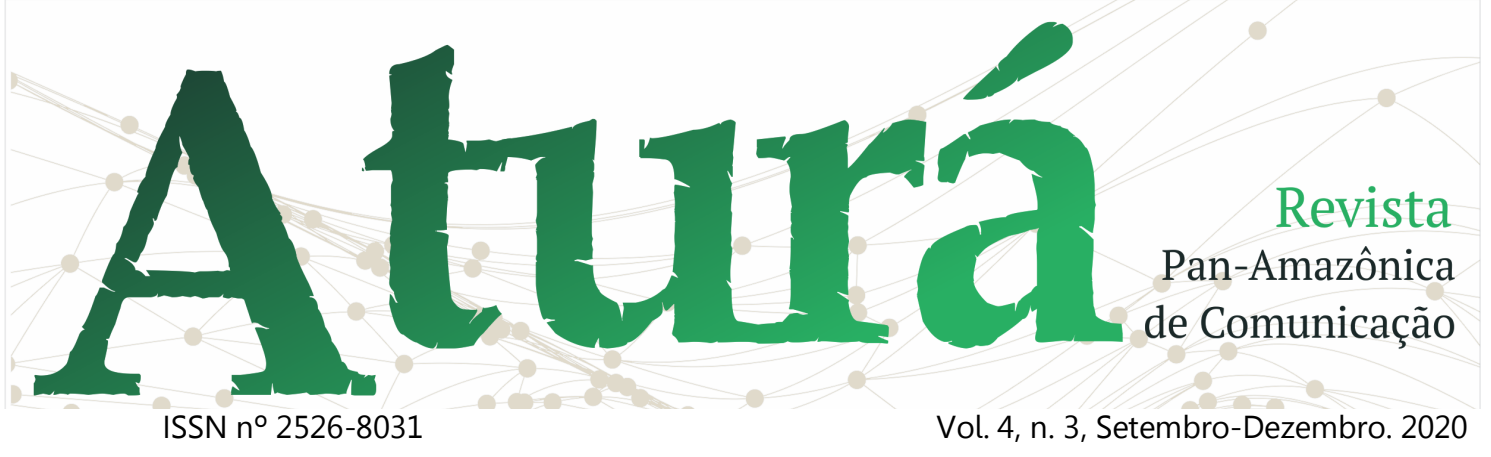

interpretação se torna um importante elo de ligação entre a filosofia e as ciências históricas, ela se torna um elemento principal para a fundamentação das ciências humanas (DILTHEY, 1999, p.32).

O filósofo Hans Gadamer (2017) se volta para a ontologia hermenêutica, o Dasein, o ser-aí no mundo já trabalhado anteriormente por Heidegger (2017). Ele chama atenção para a pré-compreensão de um texto, o qual é feito pelo intérprete a partir de sua própria visão do mundo, recebendo, portanto, essa interpretação, uma ideia pré-concebida em um primeiro momento. Gadamer orienta (RICHARDSON, 2017) que essa interpretação, para se tornar mais próximo à essência, precisa ser revisada, pois na medida que abandonamos essa projeção inicial sobre o texto, capta-se com mais transparência a real essência do texto.

O caminho pavimentado de Gadamer (2017) recebe a contribuição do pensamento Ricoeur (2017), quando acrescenta que a hermenêutica não pode ser concebida sem estudar os símbolos e signos, próprios das ciências humanas, objetos comuns no campo de pesquisa da comunicação.

Isso faz sentido porque são os signos e símbolos que dão significados às coisas, portanto eles medeiam a interação entre os sujeitos. Signos e símbolos também permitem a comunicação à medida que essas imagens aliadas aos significados se entronizam nos indivíduos.

Ainda no prefácio do livro Conflito das Interpretações, feito por Miguel Dias Costa, fica claro que Ricoeur (1988) quis conciliar a fenomenologia/hermenêutica ao método tradicional de se fazer ciência, baseada no método das ciências positivistas, que tem como princípio a objetividade, o empirismo, ao questionar sobre o lugar e a tarefa das ciências filosóficas neste modo de fazer ciência, em que se aposta no todo, ainda que as partes sejam sacrificadas.

Essa é uma das principais características do trabalho do filósofo. Com esse propósito, ele inaugura o "(...) acesso à existência e à compreensão de si que passa obrigatoriamente por uma 


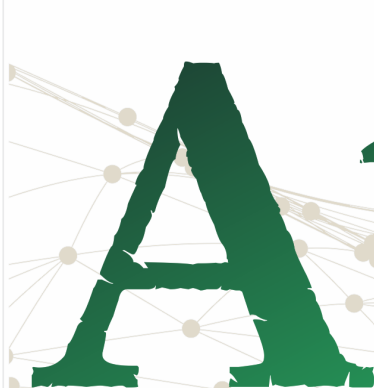

ISSN n² 2526-8031
Revista

Pan-Amazônica

de Comunicação elucidação semântica organizada em torno das significações simbólicas" (RICOEUR, 1988, p.3).

Segundo ele, só é possível observar a intencionalidade subjacente se, quem investiga, abandonar o imediatismo e intuitivismo, características comuns das ciências naturais.

A fenomenologia e a hermenêutica se complementam. Enquanto a primeira, a partir da redução fenomenológica, o pesquisador apreende a essência do objeto tal qual é o objeto para a consciência do sujeito que o apresenta, sem fazer juízo de valor, sem separar o sujeito do objeto, mas com base na experiência da pessoa; a segunda sistematiza o objeto captado, interpreta tal como foi dito, com a respectiva intencionalidade, já que toda "consciência é consciência de algo".

É o resultado desta interpretação que vai revelar o que pode estar por trás do verdadeiro sentido do objeto apreendido pelo sujeito. "Portanto, é preciso sair deliberadamente do círculo encantado da problemática do sujeito e
Vol. 4, n. 3, Setembro-Dezembro. 2020 do objecto, e interrogarmo-nos sobre o ser" (RICOEUR, 1988, p.9).

O posicionamento de Ricoeur vai ao encontro das reflexões feita por Wallerstein (1996) e outros estudiosos que compuseram um grupo bem heterogêneo, a partir da década de 80 do século passado, para debater sobre o futuro das ciências sociais, que apesar, do ponto vista estrutural ter crescido com o surgimento de vários institutos de pesquisas, observou um agravamento em relação ao realinhamento das ciências sociais nas estruturas organizacionais.

Chegou-se a um consenso de que naquele momento havia um desencantamento do mundo. E como fazer ressurgir esse encantamento do mundo? Acreditava-se ser necessário a busca pelo conhecimento, não se limitando a uma sabedoria ou ideologia aceita, pronta.

Observou-se que as ciências sociais não representavam uma demanda da história escrita em nome das estruturas do poder existente, que tratava as demandas de forma objetiva, sem levar 


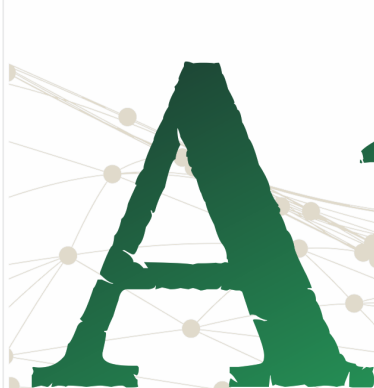

ISSN n०2526-8031

\section{Revista}

Pan-Amazônica

de Comunicação

Vol. 4, n. 3, Setembro-Dezembro. 2020

em conta as particularidades dos grupos de indivíduos dentro do seu contexto histórico, cultural e social.

O reencantamento com o mundo passava necessariamente pela quebra de barreiras artificiais de um Estado construído numa visão nomotética fechada, voltados apenas para a política, economia e social. Havia a necessidade da investigação, de se ter um olhar mais plural, colocando no centro do debate seres humanos e a natureza, já que ambos são parte do universo e seguem o curso do tempo. A ideia era, e ainda é, libertar cada vez mais o pensamento humano.

E Wallerstein deixa claro que não seria fácil colocar em prática essa ideia de libertar o pensamento humano, porque se esbarraria em alguns fatores como: a crença baseada na neutralidade; a inserção do tempo e espaço como variáveis das análises; superar as separações política, econômica e social, cultural ou sociocultural, pois os cientistas sociais costumavam ignorar essas linhas. Mas ele argumenta que
Se o pesquisador não pode ser neutro e se o tempo e o espaço são variáveis internas na análise, segue-se que a tarefa de reestruturar as ciências sociais deve ser o resultado da interação de estudiosos de todos os climas e de todas as origens. Perspetivas (levando em consideração gênero, raça, classe e culturas linguísticas), é que essa interação global é real e não uma mera cortesia formal que esconde a imposição das opiniões de um segmento de cientistas do mundo." (WALLERSTEIN. 1996.p.83) $)^{2}$

O autor reconhece que diante de tantas implicações não será fácil reestruturar as pesquisas em ciências sociais, mas ressaltou que, na medida em que essas discussões avançam, poderão nortear o caminho da solução.

Alerta que apesar dos conceitos de utopias estarem relacionados com o possível progresso, é preciso se levar em conta que esse progresso não depende apenas das ciências naturais, como se pensava outrora. $O$ progresso exige criatividade humana para desvendar as

\footnotetext{
${ }^{2}$ No original: (...) si el investigador no puede ser neutral y si el tiempo y el espacio son variables internas en el análisis, entonces se sigue que la tarea de reestructuración de las ciencias sociales debe ser resultado de la interacción de estudiosos procedentes de todos los climas y de todas las perspectivas (tomando en cuenta género, raza, clase y culturas lingüísticas), y que esa interacción mundial sea real y no una mera cortesía formal que encubra la imposición de las opiniones de un segmento de los científicos del mundo (WALLERSTEIN, 1996, p. 83).
} 


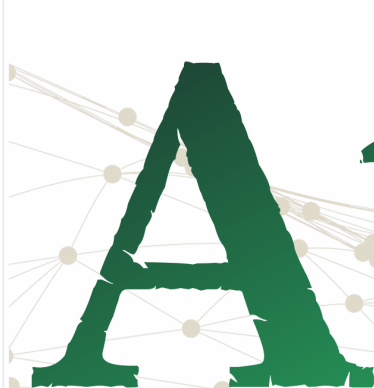

ISSN n²526-8031

\section{Revista}

Pan-Amazônica

de Comunicação

Vol. 4, n. 3, Setembro-Dezembro. 2020 questões complexas que permeiam 0 mundo complexo.

A racionalidade deve continuar presente, mas é preciso ser um racional que acompanha a evolução do tempo, observando os erros cometidos no passado, quando os problemas sociais que necessitavam de políticas públicas eram entregues aos intelectuais, cientistas que definiam fenômenos particulares como universais, para resolver questões da política imediata, analisando os problemas do ponto vista analítico, como se a vida em sociedade fossem números, que pudesse ser resolvida por meio da matemática, sem analisar a complexidade que o problema exige, que passa necessariamente pelo estudo do ser humano e da natureza, como partes indissociáveis.

Wallerstein lembra que durante um século (1850 a 1950) os cientistas sociais olhavam o Estado e reverberavam nas suas pesquisas como um Estado analítico, e que somente em 1970 as vozes se unificaram e passaram a ver o Estado como fronteira da vida social, sendo, portanto, objeto de questionamentos sérios, uma vez que os estados estagnaram, não cumpriram o papel de se desenvolver, e consequentemente, promover o bem-estar econômico da sociedade. Além disso, a expansão do conhecimento trouxe um novo olhar, discutindo questões que antes não eram questionadas.

Nas últimas décadas as indagações sobre o papel das ciências sociais voltaram novamente ao centro da discussão, uma vez que houve a expansão da tecnologia e o mundo não é mais pensado de forma local, mas global, levando os estados a se repensarem enquanto instituição que tem que prover o bem-estar e levar segurança aos que neles vivem.

Para o autor, o grande problema é que esses estudos globalizados e analitizados se basearam em comparações entre os estados, ao invés de investigar as características típicas de cada localidade, levando em consideração diversos fatores que 


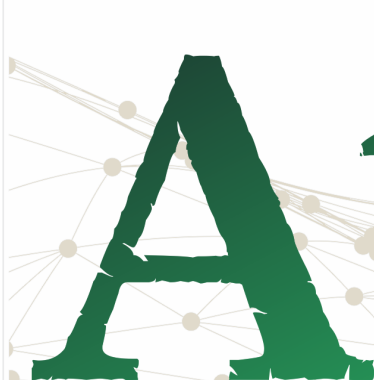

ISSN n² 2526-8031
Revista

Pan-Amazônica

de Comunicação compõem grupos que vivem em sociedade.

Mas os erros do passado, quando a ciência social era voltada apenas para objetividade, tem um papel importante neste contexto de reestrutura das ciências sociais. Ressalta que nos estudos de ciências sociais a objetividade deve estar aliada à subjetividade nas investigações, pois dessa forma contribuirá não somente para estruturar os estudos voltados para as ciências sociais, mas sobretudo ampliar e promover a inclusão de acordo com as particularidades de cada grupo de indivíduo com suas múltiplas experiências culturais. Em outras palavras, dá lugar aos estudos plurais e universais.

Neste mesmo diapasão, o filosófo Edgar Morin (1921), ao tratar sobre o desafio da complexidade, mostra que esse desafio passa, necessária/obrigatoriamente, por mudanças de paradigmas, de se ter múltiplos olhares sobre as partes que constituem o todo e sobre o todo que é constituído pelas partes, pois o todo só é todo porque não é fragmentado.
Ao usar o tetragrama - ordem, desordem, interação e organização - para explicar o caminho para se compreender a complexidade, ele deixa claro que essa análise complexa exige um tur com olhares atentos à transdisciplinaridade. Ao citar o filósofo, químico e poeta, Gaston Bachelard (2006), Morin lembra que sua obra se preocupava com a complexidade nas pesquisas científicas, ao "considerar a complexidade como um problema fundamental" (apud MORIN, 2005. p.175), bem como já havia sido mencionada no século XIX pelo matemático estadudiniense, Warren Weaver, ao afirmar que século 19 seria o século da complexidade desorganizada, e que somente no século seguinte se tornaria organizado.

Morin (2005) se contrapôs ao matemático, apenas no que diz respeito à data profetizada, ao assegurar que essa organização iniciaria neste século XXI. O argumento de Morin aponta para o fato de que um dos mal-entendidos da ciência é querer tratar a complexidade como uma receita de bolo, ao invés de vê-la como 


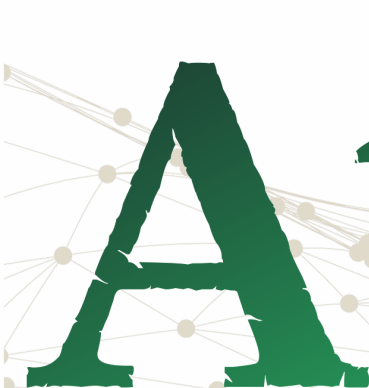

ISSN n² 2526-8031
Revista

Pan-Amazônica

de Comunicação

Vol. 4, n. 3, Setembro-Dezembro. 2020

um desafio em que a atividade pensante é inerente a esse processo. A crítica dele é exatamente à linha objetiva da ciência, que simplifica o processo, analisando o todo sem esmiuçar as partes.

"O segundo mal-entendido é confundir complexidade com completude" (MORIN, 2005, p.176), simplificando-se a complexidade das partes que formam o todo. E é neste diapasão que ele chama a atenção para dizer que na complexidade estão as unidades que formam as dezenas, centenas, milhares, e assim sucessivamente. O filósofo destaca que as ciências sociais assim como as ciências naturais precisam ser religadas, pois há muito tempo os estudos científicos estão fragmentados. É hora de religar os pontos, reconstruir a ciência para melhor compreensão.

Para Morin (2005, p.175),

A complexidade é aquilo que tenta conceber a articulação, a identidade e a diferença de todos esses aspectos [...] A ambição da complexidade é prestar contas das articulações despedaçadas pelos cortes, entre disciplinas, entre categorias cognitivas e entre tipos de conhecimento.

Ao tratar da complexidade como fenômeno multidimensional, Morin (2005) abre um leque para se pensar nas multidimensões que envolvem uma sentença, a profundidade de um pensamento multidimensional. $E$ se é multidimensional, então pode ser tanto mensurável para determinados aspectos quanto imensuráveis para outros, afinal "(...)não podemos chegar à complexidade por uma definição prévia; precisamos seguir caminhos tão diversos que podemos nos perguntar se existem complexidades e não uma complexidade". (Morin, 2005, p.177)

Chama a atenção quando afirma que o desafio da complexidade não é um fenômeno empírico por vários motivos, mas que o empirismo deve dialogar sempre com o pensamento racional. $E$ que para se pensar e fazer ciência com consciência é preciso se levar em conta a "ordem, desordem e organização" premissas que resulta em problemas, e estes por sua vez buscam respostas e 


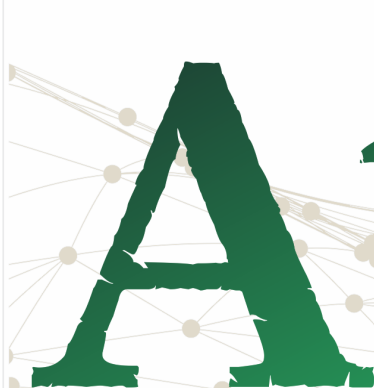

ISSN n² 2526-8031
Revista

Pan-Amazônica

de Comunicação

Vol. 4, n. 3, Setembro-Dezembro. 2020 soluções, além de fugir da crise de conceitos fechados que levam a "verdade". Mas que verdade? Aquela que é compreendida pelas lentes do pesquisador ou a aqueles que se reflete nas múltiplas realidades do objeto pesquisado?

A organização minuciosa das partes para chegar ao todo pode trazer à tona o que está subjacente - justamente o que defende a fenomenologia e a hermenêutica - fazendo emergir culturas e modos de vida que não eram contemplados em sociedades complexas, digamos assim, com efetivas políticas públicas, uma vez que essas foram feitas para atingir o todo sem observar a singularidade dos atores nela inseridos, pois parte e todo são intrínsecas, afinal de contas "(...) o processo social é um círculo produtivo ininterrupto no qual, de algum modo, os produtos são necessários à produção daquilo que os produz" (MORIN, 2005, p. 182).

Como diria Pascal apud Morin, (2005, p.181): "Só posso compreender um todo se conheço, especificamente, as partes, mas só posso compreender as partes se conhecer o todo". E como essa afirmativa dá a ideia - também - de um ciclo vicioso, Morin (2005, p.182) explica que "(...) a inteligibilidade dos fenômenos globais ou gerais necessita de circuitos e de um vaivém entre os pontos individuais e o conjunto".

Como podemos observar, todos os filósofos citados coadunam, de certa forma, com esse novo olhar de se fazer ciência, e os estudos fenomenológicos / hermenêuticos podem ser um caminho profícuo nas investigações científicas. Todas essas questões levantadas por Morin vão ao encontro do pensamento de Immanuel Wallrestein, autor de Abrir Las Ciência Sociales (1996), que diz que é preciso aprender com os erros do passado ao salientar que nos estudos de ciências sociais a objetividade deve estar aliada à subjetividade nas investigações.

"Complexus do complexus" é uma expressão cunhada por Morin para explicar que a complexidade é a reunião de outros elementos complexos, os quais surgem como uma velha toupeira 


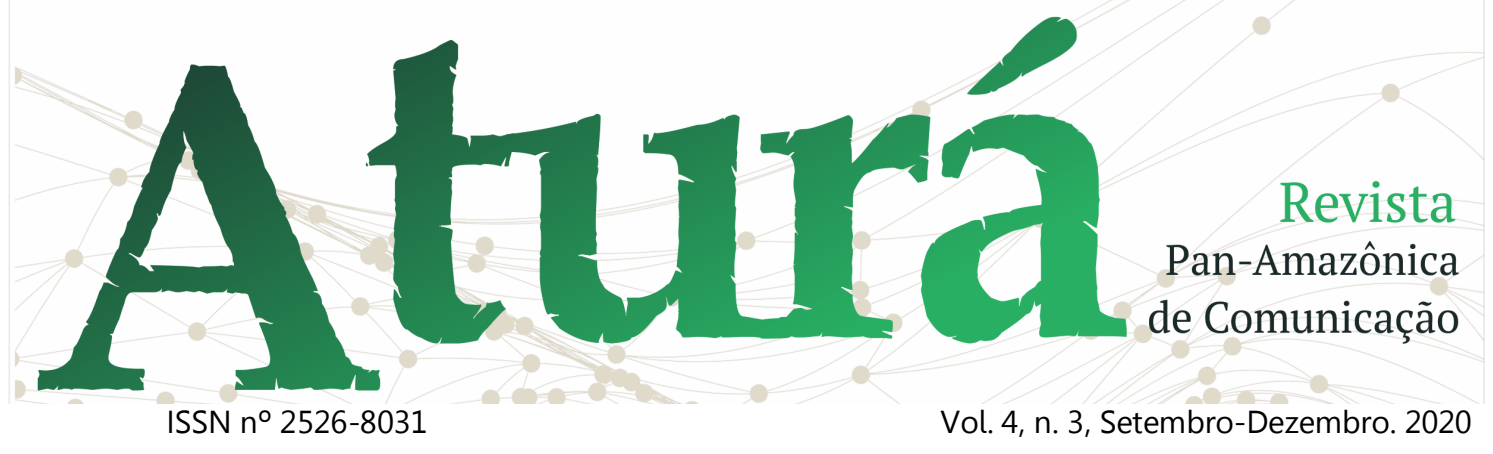

(expressão marxista), que aparentemente estaria adormecida, mas que emergem por conta dessa desordem, cujos fios se entrelaçam.

É fato que na complexidade reside a incerteza. E assim é, pelo fato de se contestar o que era tido como absoluto, imexível, legítimo, verdadeiro na regência do mundo, que está posto há muito tempo. Mas o que parece em um primeiro momento negativo, e que até pode dar a ideia de regressão, por causar desordem, pode ser a chave para um conhecimento baseado na compreensão. A dialógica é o caminho para unidualidade que mostrará que "o homem é um ser unidual, totalmente biológico e totalmente cultural a um só tempo" (MORIN. 2005, p.189). Seguindo a dialógica, o filósofo esclarece que

O objeto do conhecimento não é o mundo, mas a comunidade nós-mundo, porque o nosso mundo faz parte da nossa visão do mundo, que faz parte do nosso mundo. Em outras palavras, o objeto do conhecimento é a fenomenologia e não a realidade ontológica Essa fenomenologia é a nossa realidade de seres no mundo" (MORIN, 2005, p.205).
E para conectar ainda mais os fios que ligam a fenomenologia/ hermenêutica na base de uma investigação científica fora dos padrões considerados normais - que se preocupa apenas em sistematizar o conhecimento com base na realidade, desde que comprovada empiricamente - Bachelard (2006) auxilia nesta compreensão.

Mas antes disso, atenho-me às considerações de Thomas Khun (1998, p.35), ao cunhar o termo "ciência normal", que ao criticar o modelo pragmático de se fazer ciência, afirma que "(...) a ausência de uma razão para procurar alguma informação mais recôndita, a coleta inicial de fatos é usualmente restrita à riqueza de dados que estão prontamente a nossa disposição". Nesta mesma esteira de pensamento está Paul Feyerabend (2015), que também se opõe à absolutização de uma verdade e aos métodos da lógica.

Voltando a Bachelard (2006), é importante explicar que ele rompe com a epistemologia do conhecimento tradicional ao focar nas leis da física e da 


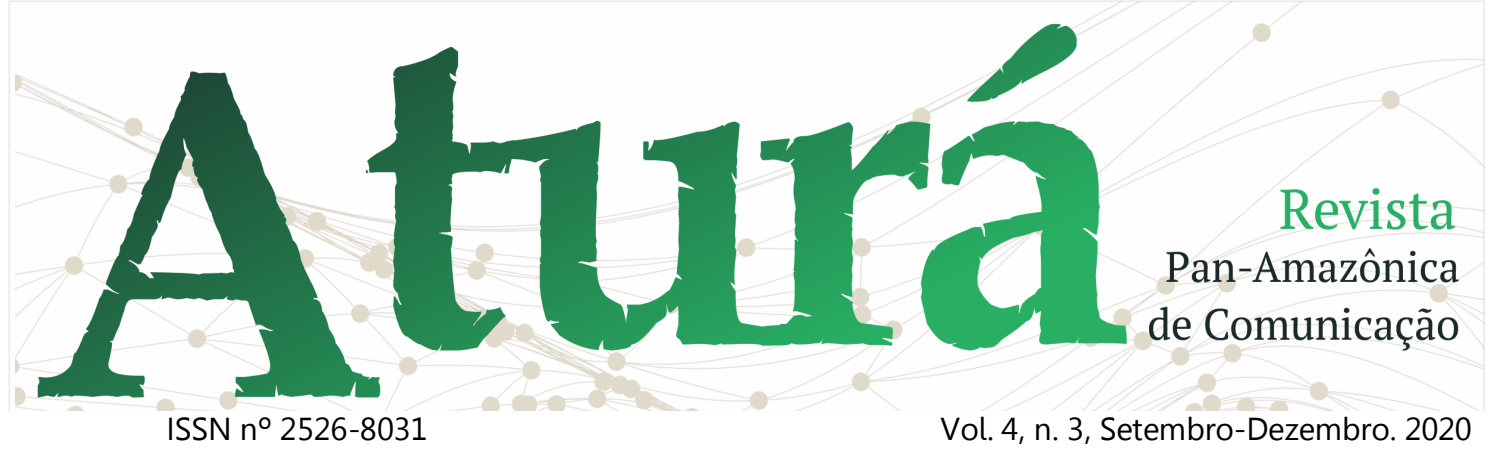

química. Segundo ele, para o espírito positivista, a balança era um instrumento suficiente para determinar os pesos atômicos.

Ocorre que a balança não era mais suficiente, a partir da descoberta da Isotopia, no século $\mathrm{XX}$, para separar e pesar os isótopos (elementos que possuem mesmo número atômico, porém números de massa diferentes, uma descoberta importante para ciência, principalmente para descobrir a idade de um objeto e de uma pessoa, portanto muito usado para desvendar crimes misteriosos), pois se havia a necessidade de uma técnica indireta, e que o "(...)simples facto do caráter indirecto das determinações do real científico já nos coloca num reino epistemológico novo (BACHELARD, 2005, p.18). Com essa compreensão o filósofo relativiza o objeto, portanto a verdade não é tão absoluta.

Ele intitula um dos capítulos do livro de "preguiça" da filosofia para dizer que há uma negligência com a filosofia do conhecimento no quadro geral da filosofia contemporânea, e que isso reduz a ciência a uma "pequena aventura", e propõe que "a filosofia científica renuncie ao real imediato e que ajude a ciência na sua luta contra as instituições primeiras" (2005, p.26).

Ora, o que é essa afirmação de Bachelard (2005) senão a de ir ao encontro do pensamento de Husserl quando defende a fenomenologia transcendental?

\section{Considerações finais}

Revisando trabalhos científicos dissertações e teses - dos últimos cinco anos voltados para estes conceitos, ao aplicar as palavras-chave de "fenomenologia + hermenêutica + comunicação"; encontrou-se no banco de dados do Portal de Periódicos da Capes ${ }^{3}$ e também da SCielo $^{4}$, vários arquivos voltados para a temática fenomenologia/hermenêutica em

\footnotetext{
${ }^{3}$ Capes. Portal de Periódicos da. Catálogo de teses e dissertações. http://catalogodeteses.capes.gov.br/catalogoteses/\#!/. Acessado no dia 18/-7/2021.

4 SCIELO. Scientific Electronic Library Online. https://www.scielo.org/. Acessado no dia 17/07/2021
} 


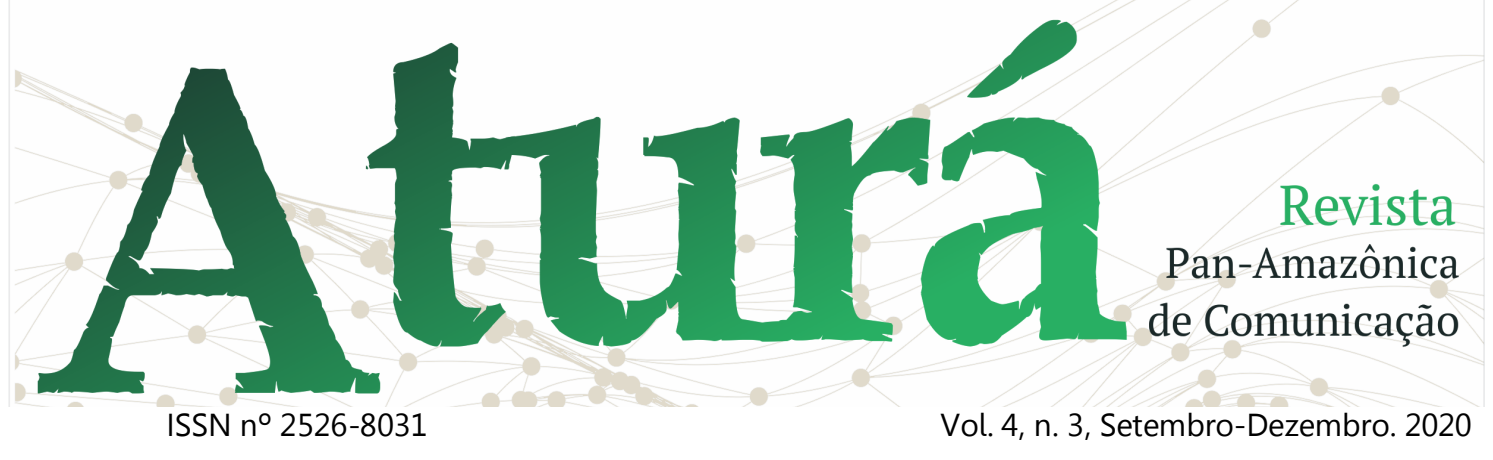

diversas áreas do conhecimento, porém poucos na área de comunicação, jornalismo, e nenhum contendo as três palavras focando especificamente no rádio como meio de comunicação.

Nada também fora identificado ao usar a palavra-chave "fenomenologia +hermenêutica+comunicação+memória", que abarca meu objeto de estudo. A pesquisa foi feita no dia 11 de julho, quando foram encontrados na Portal da Capes uma tese de doutorado abrangendo(fenomenologia/hermenêutic a/comunicação) do ano de 2018.

Encontramos também trabalhos, tese e dissertação, abordando a "fenomenologia + comunicação", bem como uma tese em com as palavraschave "hermenêutica + comunicação".

Ao se pesquisar pelas palavraschaves "hermenêutica + jornalismo" e "fenomenologia + jornalismo" foram detectados um total de oito trabalhos, entre teses e dissertações, apenas relacionada a primeira opção. A pesquisa também detectou uma dissertação no campo do Radiojornalismo focando a "fenomenologia + radiojornalismo"

Como se percebeu ao longo da pesquisa, a fenomenologia e a hermenêutica são temas ricos, mas pouco utilizados no âmbito das pesquisas em comunicação, pelo menos nos últimos cinco anos.

Aliar a arte da interpretação ao desvendamento da essência do fenômeno no campo da comunicação, que se dá no ser-com-outros, elemento inerente à natureza das relações comunicacionais, para desnudar o que está nos recônditos da memória e dos saberes amazônicos, me parece ser de grande relevância para a comunidade científica e, principalmente, para a pesquisa em comunicação na Amazônia.

\section{Referências}

BACHELARD, Gaston. A epistemologia. Tradução: Fátima Lourenço Godinho e Marino Carmino Oliveira. Edições 70. LDA, 2006

BARCELLOS, André. Isótopos: o que são e o que fazem? Disponível em: http://eurekabrasil.com/isotopos-o-que-saoe-o-que-fazem/ . Acessado em: 17/07/021 


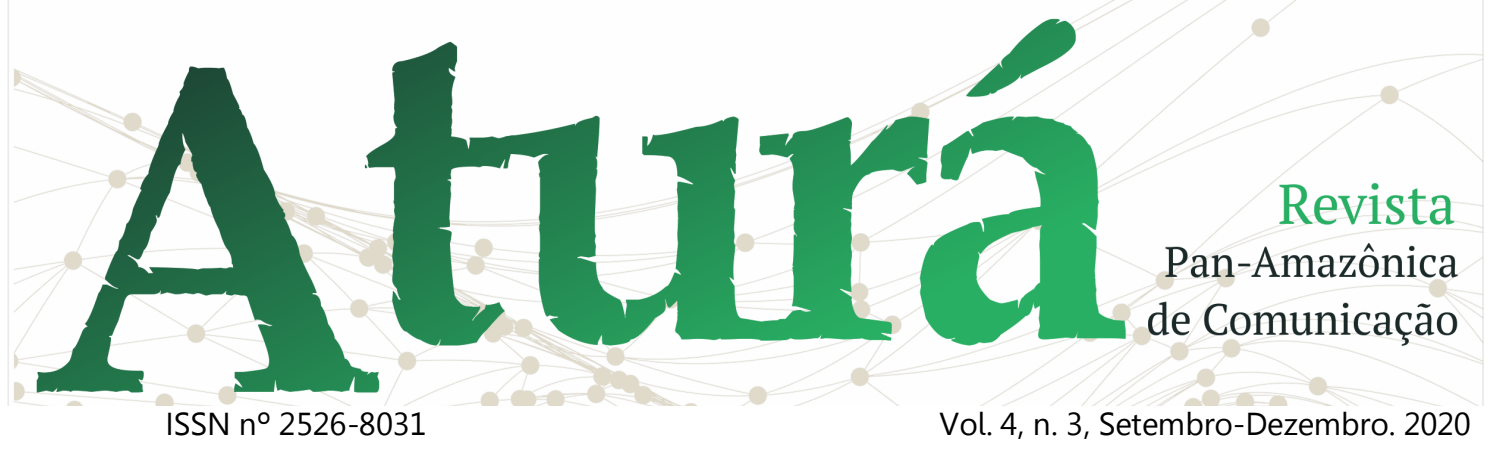

BOLAÑO César; DRUETTA Delia Crovi; e CIMADEVILLA Gustavo. La contribución de América Latina al campo de la Comunicación - Historia, enfoques teóricos, epistemológicos y tendencias de la investigación. Ano 2014.

CASTRO, Fábio Fonseca de. Fenomenologia da Comunicação em sua Quotidianidade. Intercom - RBCC. São Paulo, v.36, n.2, p. 2139, jul./dez. 2013

Capes. Portal de Periódicos da. Catálogo de teses e dissertações. http://catalogodeteses.capes.gov.br/catalogo -teses/\#!/. Acessado no dia 18/-7/2021

CHEUNG, Helier. BBC News em Bergen (Noruega): A misteriosa morte da 'mulher de Isdalen', o enigma que a Noruega tenta resolver há quase 5 décadas. Disponível em: https://www.bbc.com/portuguese/geral39920129. Acessado em: 17/07/021

DILTHEY. Wilhelm 0 surgimento da Hermenêutica. Numen; revista de estudos e pesquisa da religião. Tradução: Eduardo Gross Revisão: Luís H. Dreher. Juiz de Fora, v.2. n.l, p. 11-32. Ano 1999. https://periodicos.ufjf.br/index.php/numen/is sue/view/946. Acessado: 16 de julho de 2021

FERREIRA, Leonardo Magal de, A Hermenêutica Contemporânea: Entre texto e vida. Texto editado do original apresentado como dissertação de mestrado sob o tema "Interpretação e Existência: As proximidades entre hermenêutica e vida no período contemporâneo e o retorno ao texto em Paul Ricoeur" no dia 22 de setembro de 2017 na Universidade Metodista de São Paulo (UMESP). Disponível em: https://www.researchgate.net/publication/33 6654708 A HERMENEUTICA CONTEMPORAN EA ENTRE TEXTO E VIDA. Acessado no dia 9 de julho de 2021
FEYERABEND, Paul. Adiós a la razon, 1984. Tradução: José R. de Rivera, Retoque de cubierta: Titivillus, 2015.

HALBWACHS, Maurice. A memória coletiva. Tradução: Laurent Léon Schaffter. $2^{a}$ edição. Edições Vértice, ano 1990.

GIANI, Yuri Manzi. Epistemologia da Comunicação: Uma discussão sobre a dupla natureza do objeto comunicacional a partir de uma fenomenologia da comunicação. Dissertação (Área de Concentração: Comunicação, Cultura e Cidadania), ano 2015. Disponível em: https://sucupira.capes.gov.br/sucupira/public /consultas/coleta/trabalhoConclusao/viewTra balhoConclusao.jsf?popup=true\&id trabalho $=3683846$. Acessado no dia 11/07/2021

GOMES, Annatália Meneses de Amorim; PAIVA, Eliana Sales; VALDÉS, Maria Teresa Moreno; FROTA, Mirna Albuquerque; e ALBUQUERQUE, Conceição de Maria de. FENOMENOLOGIA, HUMANIZAÇÃO E PROMOÇÃO DA SAÚDE: UMA PROPOSTA DE ARTICULAÇÃO. Saúde Soc. São Paulo, v.17, n.1, p.143-152, 2008. Disponível em: https://www.scielo.br/j/sausoc/a/QzBvdhjG6b ynZ3ncGRppRqL/?lang=pt. Acessado: 11 de julho de 2021.

HUSSERL, Edmundo. A ideia da fenomenologia. Edições 70. Depósito Legal 32973/89. Ano 1986.

KHUN, Tomás S. A estrutura das Revoluções Científicas. $5^{a}$ Edicão. Editora Perspectivas S.a, Ano 1998.

LIMA, Marcos Antonio Martins; e MARINELLI, Marcos. A Epistemologia de Gaston Bachelard: uma rupturas com as filosofias do imobolismo. Revista de Ciências Humanas UFSC, Vol.45, No 02, pag. 393-406, 2011. Disponível em: https://doi.org/10.5007/2178- 


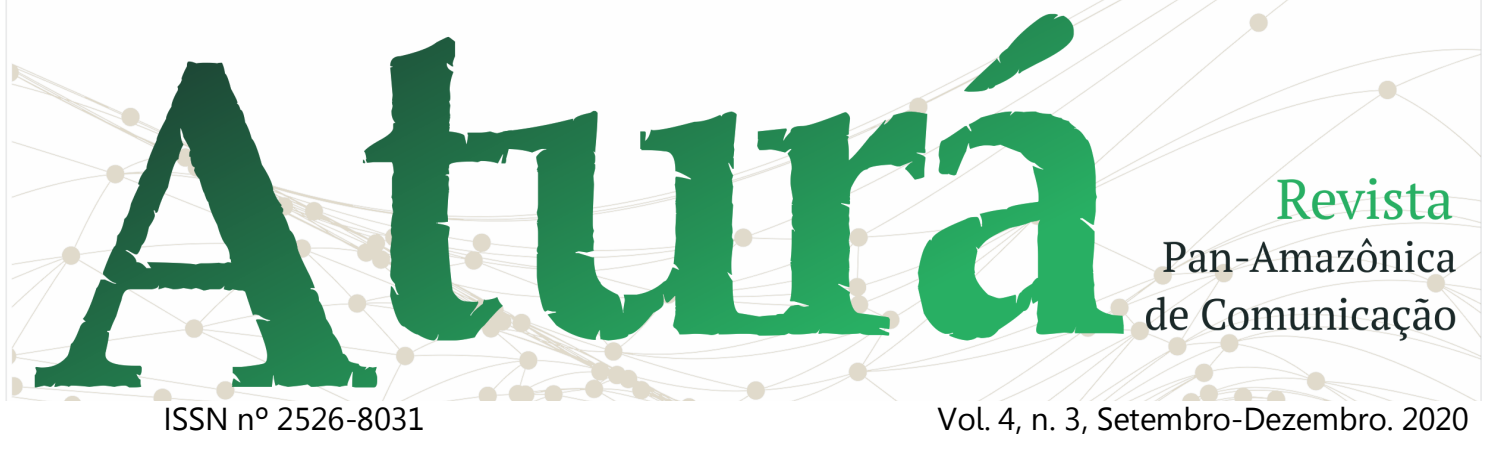

4582.2011v45n2p393. Acessado no dia $16 / 07 / 2021$.

Disponível

em:

https://sucupira.capes.gov.br/sucupira/public MARTINO, L. M. S.; MARQUES, A. C. S. Modalidades e derivações da comunicação no mundo da vida: sentidos, experiência e interação. Galaxia (São Paulo, Online), n. 31, p.105-116, abr. 2016. Disponível em: http://dx.doi.org/10.1590/1982-

25542016117217.Acessado no dia $12 / 07 / 2021$

Lconsultas/coleta/trabalhoConclusao/viewTra balhoConclusao.jsf?popup=true\&id trabalho $=2757290$. Acessado em: 12/07/2021

RICOEUR, Paul. O conflito das interpretações; Ensaios de hermenêutica. Tradução: M .F. Sá Correia. Rés-Editora. LDA. 1969.

RILKE, Rainer Maria. A hermenêutica filosófica de Hans-Georg Gadamer e a disciplina histórica: pertencimento e crítica da tradição. Disponível em: https://www.maxwell.vrac.pucrio.br/7199/7199 3.PDF. Acessado em 08/07/2021.

ROSA, Carlos Augusto de Proença. História da ciência : a ciência moderna . $2^{a}$ Ed. - Brasília FUNAG, 2012. Disponível em: http://funag.gov.br/loja/download/1022.

Historia da Ciencia - Vol.III -

Ciencia e o Triunfo do Pensamento Cientlfic o no Mundo Contemporaneo.pdf. Acessado em:16/07/2021.

RIBEIRO, Daniel. Johann Heinrich Lambert. Revista da Ciência Elementar Faculdade de Ciência da Universidade do Porto, 2014. Disponível em https://wikiciencias.casadasciencias.org/wiki/i ndex.php/Johann_Heinrich_Lambert, acesssado no dia 31/10/2021

RICHARDSON, Roberto Jarry. Pesquisa Social: Métodos e técnicas. Colaboração: Dietemar Klaus Pfeiffer, $4^{a}$ ed. Ver., atual e ampl. São Paulo: Atlas, 2017.

SANCHEZ, Devair Gonçalves. Mundo-da-vida e paradigma: apontamentos acerca da crise das ciências em Husserl e Kuhn. Revista Alamedas, Vol. 2, n.1, 2014 e-ISSN 19810253. Disponível em: http://erevista.unioeste.br/index.php/alamedas/articl e/view/10451/8167. Acessado em: 09/07/2021 


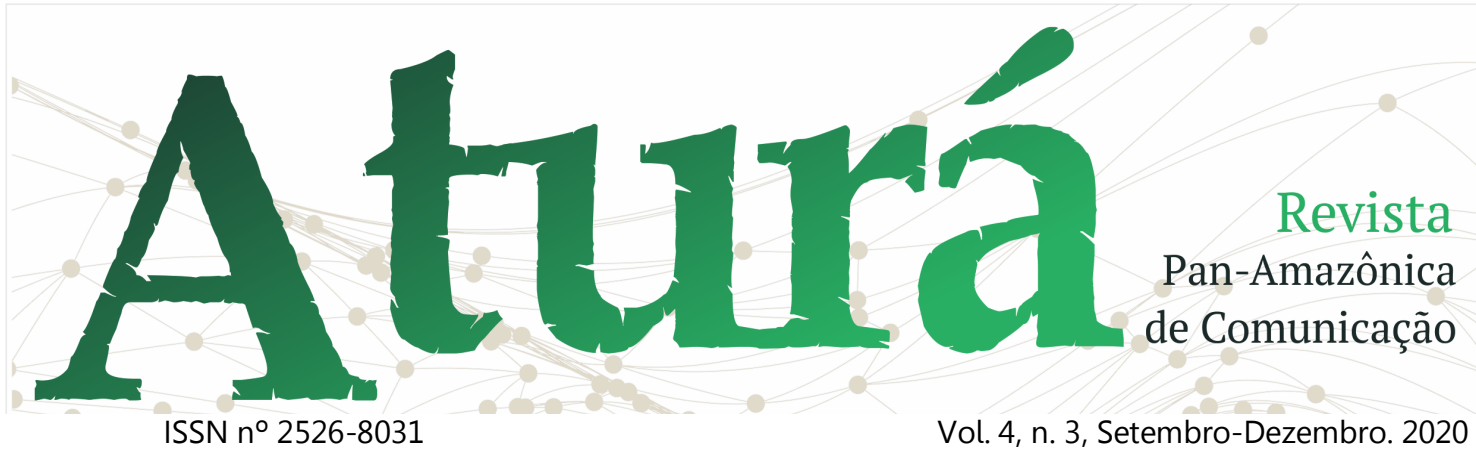

SCIELO. Scientific Electronic Library Online.

https://www.scielo.org/. Acessado no dia 17/07/2021

SOUZA, Rose Mara Vidal de; MELO, José Marques de; e MORAIS Osvando J. de (organizadores). Teorias da Comunicação: Correntes de Pensamento e Metodologia de Ensino. Intercom, São Paulo 2014.

VALVERDE, Monclar. Estética E Hermenêutica: a estética da comunicação como hermenêutica do mundo sensível. Associação Nacional dos Programas de Pós-Graduação em Comunicação XXVIII Encontro Anual da Compós, Pontifícia Universidade Católica do Riop Grande do Sul, Porto Alegre - RS, 11 a 14 de junho de 2019. Disponível em: http://www.compos.org.br/biblioteca/trabalh os arquivo YV7PUT51CJAOMVJVPLVP 28750 7170220191909 19.pdf. Acessado no dia 09/07/.2021

WALLERESTEIN, Immanuel. (coordinador). Abrir las ciencias sociales. México: Universidad Nacional Autónoma de MéxicoSiglo XXI Editores, 1996.

WOLF, Mauro. Teorias da Comunicação. $5^{a}$

Edição, Lisboa, Setembro, 1999. 